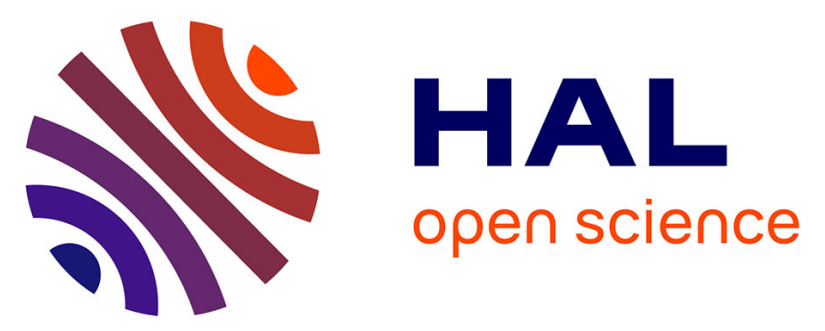

\title{
Molecular characterization of measles virus strains causing subactute sclerosing panencephalitis in France in 1977 and 2007
}

Emilie Moulin, Vanda Beal, Damien Jeantet, Branka Horvat, T.Fabian Wild, Diane Waku-Kouomou

\section{To cite this version:}

Emilie Moulin, Vanda Beal, Damien Jeantet, Branka Horvat, T.Fabian Wild, et al.. Molecular characterization of measles virus strains causing subactute sclerosing panencephalitis in France in 1977 and 2007: Molecular analysis of SSPE strains in France. Journal of Medical Virology, 2011, 83 (9), pp.1614. 10.1002/jmv.22152 . hal-00657583

\section{HAL Id: hal-00657583 https://hal.science/hal-00657583}

Submitted on 7 Jan 2012

HAL is a multi-disciplinary open access archive for the deposit and dissemination of scientific research documents, whether they are published or not. The documents may come from teaching and research institutions in France or abroad, or from public or private research centers.
L'archive ouverte pluridisciplinaire HAL, est destinée au dépôt et à la diffusion de documents scientifiques de niveau recherche, publiés ou non, émanant des établissements d'enseignement et de recherche français ou étrangers, des laboratoires publics ou privés. 
Molecular characterization of measles virus strains causing subactute sclerosing panencephalitis in France in 1977 and 2007

\begin{tabular}{|r|l|}
\hline Journal: & Journal of Medical Virology \\
\hline Manuscript ID: & JMV-11-2404.R1 \\
\hline Diley - Manuscript type: & Research Article \\
\hline Author: & 10-May-2011 \\
\hline & $\begin{array}{l}\text { Complete List of Authors: } \\
\text { Meantet, Damien; Inserm U758, Human Virology } \\
\text { Wild, T.Fabian; Inserm, human Virology } \\
\text { Waku-kouomou, Diane; Inserm, Human virology }\end{array}$ \\
\hline Keywords: & Measles, SSPE, France \\
\hline
\end{tabular}


1 Molecular characterization of measles virus strains causing subactute sclerosing

2 panencephalitis in France in 1977 and 2007

3

4 Emilie Moulin $^{1,2,3,4,5}$, Vanda Beal ${ }^{1,2,3,4,5}$, Damien Jeantet ${ }^{1,2,3,4,5}$, Branka Horvat ${ }^{1,2,3,4,5}$, T. Fabian

5 Wild $^{1,2,3,4,5}$ Diane Waku-Kouomou ${ }^{1,2,3,4,5}$

6

$7 \quad{ }^{1}$ Centre National de Référence pour la Rougeole, France

$8 \quad{ }^{2}$ Immunobiology of viral infections; Inserm, U758, Lyon, F-69365 France

$9 \quad{ }^{3}$ Ecole Normale Supérieure de Lyon, Lyon, F-69007 France

$10{ }^{4}$ IFR128 BioSciences Lyon-Gerland Lyon-Sud

$11{ }^{5}$ Université Lyon 1; 21 Avenue Tony Garnier, 69365 Lyon Cedex 07, France

12

13

14

15 Running title : Molecular analysis of SSPE strains in France

16 Key words: Measles, SSPE, France

17

18

19

20

21

22

23 


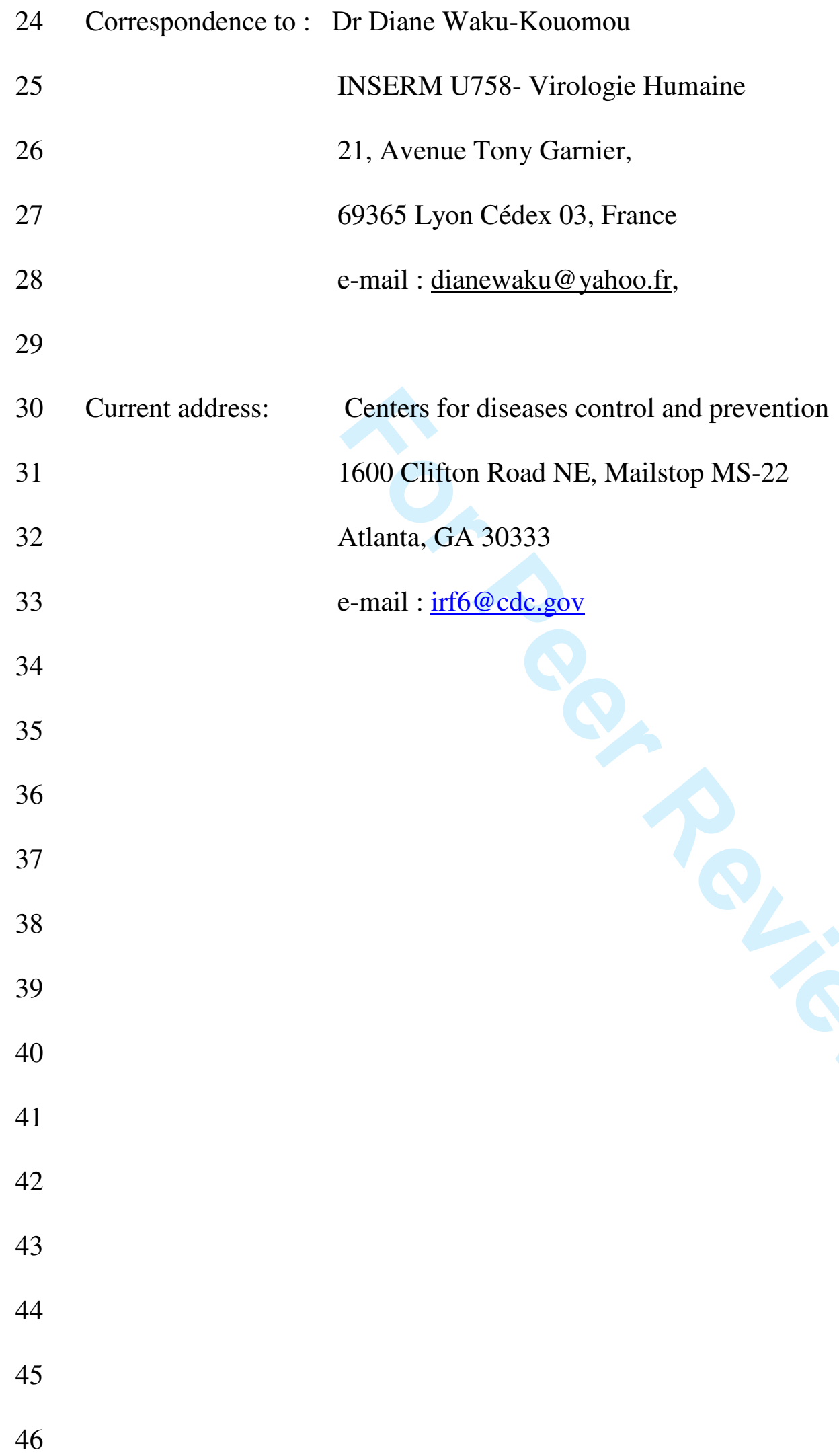


47 Abstract

48

49 Measles virus strains from two subacute sclerosing panencephalitis (SSPE) cases diagnosed in 501977 (Laine strain) and in 2007 (Hoedts strain) were studied. Phylogenetic analysis based on C-

51 terminal part of the nucleoprotein and the entire $\mathrm{H}$ gene showed that Hoedts strain, circulating in

52 France presumably in the 1980s, belonged to genotype C2. However, Laine strain, suspected to 53 have circulated between 1940s and 1960s, could not be assigned to any known measles virus 54 genotypes. Sequences analysis of the Laine strain suggested that it originated from a measles 55 virus that may have circulating at the same period as the Edmonston strain. The analysis of the 56 whole genome of both SSPE strains revealed biased hypermutations in M, F and H gene. Some 57 of these mutations like the L165P found in the M protein sequence of the Laine strain, the amino 58 acid position 94, where a mutation M94V was found in the F protein sequence of the Hoedts 59 strain are known to play an important role in the glycoprotein interaction and to impair the ability 60 of measles virus strain to produce cell-free infectious viral particles. This is the first study on 61 molecular characterization of the entire coding region of measles virus isolated from SSPE cases 62 in France.

63 64 65 66 67 68 69 


\section{Introduction}

71 Subacute sclerosing panencephalitis (SSPE) is a fatal disease of the central nervous system that

72 generally develops 7 to 10 years after infection by the measles virus. However, even with the

73 elimination of measles, cases of SSPE may still occur 20 to 30 years later because of the skew of

74 the latency distribution. Despite the availability of efficient vaccines and widespread vaccination,

75 measles remains a major cause of child mortality worldwide. An estimated 164000 people died

76 from measles in 2008 [WHO, 2009]. SSPE is caused by a persistent measles virus infection of

77 the brain. According to the WHO, the incidence of SSPE is approximately 4-11 cases per 100

78000 cases of measles [WHO, 2006]. Clinical manifestations of SSPE include behavioral

79 abnormalities, cognitive decline, myoclonic jerks, seizure and abnormalities in vision [Garg,

80 2008; Mahadevan et al., 2008]. Death generally occurs 1 to 3 years after onset of symptoms. The

81 reason why measles virus persists in some individuals is unknown, but is likely to be host

82 related.

83 Measles virus belongs to the paramyxovirus family and is a member of the Morbillivirus genus.

84 It is an enveloped virus whose genome contains six genes that encodes for six structural proteins:

85 nucleocapsid protein $(\mathrm{N})$, phosphoprotein $(\mathrm{P})$, matrix protein $(\mathrm{M})$, fusion protein $(\mathrm{F})$,

86 haemagglutinin $(\mathrm{H})$ and large protein $(\mathrm{L})$. The $\mathrm{P}$ gene also encodes several other proteins $\mathrm{C}, \mathrm{V}$,

87 and W. Sequence analysis of SSPE viruses indicate that they differ from wild-type viruses due to

88 the introduction of several mutations that mainly affect the matrix, haemagglutinin, nucleocapsid

89 and fusion genes [Ayata et al., 2007; Jiang et al., 2009]. These genetic mutations in SSPE virus

90 result in poor expression of envelope proteins. Consequently, the SSPE virus is able to maintain

91 a persistent infection in neuronal cells of the brain but is unable to produce transmissible

92 infectious viral particles [Oldstone et al., 2005]. 
93 In France, a nationwide case-based mandatory reporting of measles cases was established in 94 2005. The vaccination coverage was approximately $87 \%$ at 24 month of age in 2005 [Waku95 Kouomou et al., 2010]. This is lower than the 95\% requested to stop the circulation on measles 96 virus in the population. As result, a number of measles outbreaks were reported in recent years 97 [Waku-Kouomou et al., 2006; Waku-Kouomou et al., 2010; Waku-Kouomou et al., 2007; 98 Zandotti et al., 2004]. Although the surveillance of measles is now well established in France, 99 information regarding SSPE cases is very rare. From 1980 to 1996, around 10 to 30 cases of 100 SSPE were reported each year by the Renaroug network [Ministère-de-la-santé-DGS, $1012008]$.With the introduction of the vaccination campaign in 1983, the number of measles cases 102 was reduced drastically and SSPE cases also dropped from 25 in 1980 to 3 cases in 1996. 103 Recently, molecular biology techniques were used to help in the diagnosis of an SSPE case 104 [Souraud et al., 2009]. However, up until the present, there has been no molecular data regarding 105 measles strains causing SSPE in France.

106

107 The purpose of this study was to describe the detection and molecular characterization of 108 measles viruses isolated in two SSPE cases diagnosed in 1977 (Laine strain) and in 2007 (Hoedts 109 strain) and also to document molecular epidemiological data of measles virus strains in France. 110 In the present study the sequences of the whole coding region of the two SSPE measles virus 111 strains isolated from brain specimens were sequenced and analyzed.

112 Phylogenetic analysis showed that Hoedst strain belonged to genotype C2 while Laine strain 113 could not be related to any known measles virus genotype. The analysis of the whole genome of 114 both SSPE strains revealed biased hypermutations in $\mathrm{M}, \mathrm{F}$ and $\mathrm{H}$ gene. This study describes for 
115 the first time molecular characterization of the entire coding region of measles virus isolated

116 from SSPE cases in France.

117

118

119

120

121

122

123

124

125

126

127

128

129

130

131

132

133

134

135

136

137 


\section{$138 \quad$ Material and method}

139 Patient, specimen, cells and viruses

140 Brain biopsy specimens obtained from 2 patients were investigated. In both cases, diagnosis was 141 confirmed clinically, by magnetic resonance imaging (MRI) of the brain or by the presence of 142 measles antibody in cerebrospinal fluid (CSF). Clinical and virological studies information of 143 these cases were published previously [Souraud et al., 2009; Wild et al., 1979].

145 Patient 1. A 38 year-old male patient who died 3 months after developing clinical symptoms. 146 The CSF globulin level was elevated, constituting $45.5 \%$ of the total protein. In the brain biopsy, 147 measles antibodies were found. A measles virus strain (Laine strain), was isolated by co-culture 148 of the brain biopsy with vero cells [Wild et al., 1979]. This measles strain was stocked in liquid 149 nitrogen since his isolation in 1979 and thaw only recently for sequence analysis.

150 Patient 2. In a 25 year-old male patient who died after 2 months course of SSPE, the MRI of the 151 brain showed hyperintensity in the grey matter and the subcortical white matter [Souraud et al., 152 2009]. Measles antibody in the CSF was excessively high at 14,000 UI/L. Measles virus 153 sequences were obtained from the brain biopsy by PCR (Hoedts strain).

154 It is assumed that the patients were infected during their childhood. However, virus sequences 155 corresponding to these periods are not available, so the Laine strain was compared to the 156 Edmonston wild type strain while the Hoedts strain which was a measles virus circulating in the 157 1980s was compared with a wild type strain in the corresponding genotype. Measles virus strains 158 analyzed in this study are summarized in table 1. 
161 RNA extraction and genome amplification

162 Viral RNA from SSPE cases was extracted either directly from clinical specimens (brain biopsy 163 for Hoedts strain) or from infected vero cells (Laine strain) using the RNA Now kits (Biogentex 164 Inc, Seabrook, South Carolina, USA) in accordance with the manufacturer's protocol.

165 Measles virus RNA was reverse-transcribed at $42^{\circ} \mathrm{C}$ for $30 \mathrm{~min}$ followed by a denaturation step 166 for $5 \mathrm{~min}$ at $85^{\circ} \mathrm{C}$ using iScript cDNA Synthesis Kit (Biorad, Marnes la Coquette, France). The 167 resulting cDNA was used as a template for PCR amplification of $\mathrm{N}, \mathrm{P}, \mathrm{M}, \mathrm{F}$ and $\mathrm{H}$ genes168 specific sequences. The $\mathrm{H}$ gene was amplified as described previously [Kouomou et al., 2002]. 169 To amplify $\mathrm{F}$ and $\mathrm{N}$ genes, PCR were performed starting by a denaturation step at $94^{\circ} \mathrm{C}$ for $1705 \mathrm{~min}$, followed by 35 cycles of denaturing at $94^{\circ} \mathrm{C}$ for $30 \mathrm{sec}$, annealing at $56^{\circ} \mathrm{C}$ for $45 \mathrm{sec}$ and 171 extension at $72^{\circ} \mathrm{C}$ for 2 min with a final extension at $72^{\circ} \mathrm{C}$ for $7 \mathrm{~min}$. The PCR cycling program 172 for $\mathrm{P}$ and $\mathrm{M}$ genes differed from that of $\mathrm{F}$ gene by only the annealing temperature, which was $17359^{\circ} \mathrm{C}$ for $\mathrm{P}$ gene and $55^{\circ} \mathrm{C}$ for $\mathrm{M}$ gene.

174 In order to amplify the L gene, measles virus RNA was reverse-trascribed at $42^{\circ} \mathrm{C}$ for $90 \mathrm{~min}$ 175 followed by a denaturation step for $5 \mathrm{~min}$ at $85^{\circ} \mathrm{C}$ using iScript Select cDNA Synthesis Kit 176 (Biorad, Marnes la Coquette, France). The L gene was amplified as seven overlaping fragments.

177 The PCR Program consisted of a denaturation step at $94^{\circ} \mathrm{C}$ for $5 \mathrm{~min}$, followed by 35 cycles of 30 $178 \mathrm{sec}$ at $94^{\circ} \mathrm{C}, 45 \mathrm{sec}$ at $57^{\circ} \mathrm{C}, 2 \mathrm{~min}$ at $72^{\circ} \mathrm{C}$, with a final extension at $72^{\circ} \mathrm{C}$ for $7 \mathrm{~min}$. Primers 179 sequences used in this study are listed in table 2.

180

181 Nucleotides Sequences determination and analysis

182 PCR products were separated by electrophoresis using a 1.2\% agarose gel and then purified 183 using the nucleospin Extract II kit (Macherey-Nagel, Düren, Germany) following the 
184 manufacturer's instructions. Sequencing was performed using an ABI 3730 (Applied 185 Biosystems, Langen, Germany). The nucleotides sequences of the N, P, M, F, H, and L gene 186 were aligned and analysed phylogeneticaly using the Molecular Evolutionary Genetics Analyses 187 (MEGA) software version 4 [Tamura et al., 2007]. Phylogenetics trees were constructed by 188 comparison of the C-terminal part of the $\mathrm{N}$ gene and the entire $\mathrm{H}$ gene of the sequences derived 189 from the SSPE strains, with the references strains defined by the WHO [WHO, 2005] using the 190 neighbour-joining method. The reliability of each tree was estimated using 1,000 bootstraps 191 replicates. The nucleotide sequences obtained in this study were deposited on Genbank under 192 accession numbers HM562894-96 (F genes), HM562897-98 (H genes), HM562899193 HM562901(L genes), HM562902-04(M genes), HM562905-07 (N genes), HM562908-10 (P 194 genes).

195

196

197

198

199

200

201

202

203

204

205

206 


\section{Results}

208

209 Phylogenetic analysis

210 Two SSPE cases were diagnosed in France; one in 1977 (Laine strain) and the other in 2007

211 (Hoedts strain). The coding regions of their entire genome were sequenced, compared to other

212 measles virus sequences available on GenBank and used for phylogenetic analysis.

213 The sequence comparison of the C-terminal part of the $\mathrm{N}$ gene with other measles virus

214 sequences available in Genbank showed that the Laine strain is related most closely to the SSPE

215 measles strain circulating in the United kingdom in 1956 (Mvs/Belfast1.UNK/1956-SSPE

216 (AF504045) [Jin et al., 2002] and Edmonston strain with 97\% identity. Phylogenetic analysis

217 based on the C-terminal part of the $\mathrm{N}$ gene showed that the Laine strain could not be assigned to 218 any known measles virus genotype (figure 1). This result was confirmed using the sequence of 219 the entire $\mathrm{H}$ gene (figure 2). To assign a new genotype, the minimum nucleotide divergence 220 should be $2.5 \%$ for C-terminal part of the $\mathrm{N}$ gene (450nt) and $2 \%$ for the full length $\mathrm{H}$ gene open 221 reading frame from the next most closely related strain [WHO, 2001a]. In this study, the 222 nucleotide divergence between the Laine strain and all measles reference strains was calculated 223 using the nucleotide sequence of the C-terminal part of the $\mathrm{N}$ gene and the entire $\mathrm{H}$ gene. The 224 results showed that for the $\mathrm{N}$ gene, the nucleotide divergence varied from $2.7 \%$ with the 225 genotype A to $5.8 \%$ with genotypes C2, D10, E, H2. Using $\mathrm{H}$ gene, the nucleotide divergence 226 varied from 2,3\% with the genotype A reference strain to 5.5\% with genotype $\mathrm{H} 1$ reference 227 strain. These results therefore suggested that the Laine strain is closer to the genotype A than to 228 any other known measles virus genotype. 
229 The most closely related measles virus to the Hoedts virus was the genotype C2 reference strain 230 and nucleotide divergence was 2.2 and 1,1\% for $\mathrm{N}$ and $\mathrm{H}$ gene respectively. Phylogenetic

231 analysis based on the C-terminal part of the $\mathrm{N}$ gene showed previously that it belonged to 232 genotype C2 [Souraud et al., 2009]. These results were confirmed in this study with the $\mathrm{H}$ gene 233 (Figure 2). The sequence comparison of the C-terminal part of the $\mathrm{N}$ gene with other measles 234 virus sequences available in Genbank showed that Hoedts strain is most close to the measles 235 strain isolated in Canada in 1984 (Monteral.CAN/14.84-AF410973) [Tipples et al., 2004] with $23698 \%$ identity and to the genotype C2 reference strain (Maryland.USA/77), isolated in the USA in 2371977 [Rota et al., 1994].

\section{Sequence variation in the coding regions of the genome of the SSPE strains}

239 The sequences of the complete coding regions of the genome of both SSPE strains (Laine and 240 Hoedts) were sequenced. They were compared to each other, to measles strains available on 241 Genbank and also with a wild type measles strain of the same genotype or a closely related 242 genotype.

243 Sequence comparison of both SSPE strains showed that, the $\mathrm{M}$ gene started by a threonine 244 (Figure 3, Table 3) instead of a methionine usually found as the start amino acids of proteins. 245 Premature stop codons were identified in the $\mathrm{F}$ gene (Figure 4) whereas the $\mathrm{H}$ gene was 246 elongated in both SSPE strains. Although the majority of mutations found were specific to each 247 strain, common mutations could be identified (Table 3). In the F protein, a mutation I446T was 248 identified. Sequence alignment on Genbank showed that this mutation is present in only 4 of the 249100 sequences analyzed. In the M gene, a mutation V101A was found whereas in the $\mathrm{H}$ protein 250 sequence, mutations R7Q and $\mathrm{Y} 12 \mathrm{H}$ were observed in this study. Along the L gene, mutations 251 Y723C and D1887N appear to be specific to both SSPE strains. 
252 Due to the fact that the Laine strain could not be assigned to any know MV genotype, the most 253 closely related wild type Edmonston strain, was used for sequence analysis of N, P, M, F, H and

254 L genes. The results showed that the amino acid sequence divergence was 3.6, 3.9, 9.5, 1.8, 3.8, 255 and $1.2 \%$ for N, P, M, F, H and L of the Laine and Edmonston strains respectively. Furthermore, 256 a T-C mutation was identified in the P/V gene which results in the replacement of the stop codon 257 of the $\mathrm{V}$ protein by a glutamine (Q 300). Therefore, the predicted V protein of the Laine strain 258 may have one more amino acid than the Edmonston strain. In the $\mathrm{M}$ gene, the start codon 259 (methionine) was altered to threonine due to a T-C change in the gene. A newly generated 260 termination codon was identified at position amino acid 350 (Table3, Figure 3). Hence, the 261 predicted $\mathrm{M}$ protein of the Laine strain may have 15 amino acids more than one of the 262 Edmonston strain (335 amino acids). Another important observation in the Laine $\mathrm{M}$ protein 263 sequence was that $66 \%$ of the mutations were L-P due to T-C mutation in the $\mathrm{M}$ gene. In the F 264 protein sequence, a T-G mutation at nucleotide position7095 results in an earlier termination 265 codon at amino acid position 546 (Table 3). This generates a predicted $\mathrm{F}$ protein which may be 4 266 amino acids shorter than the F protein of the Edmonston strain (Figure 4). Sequence analysis of 267 the $\mathrm{H}$ gene revealed that there were no termination codons. The attempts to amplify the 268 intergenic region between $\mathrm{H}$ and $\mathrm{L}$ failed. In the $\mathrm{N}$ protein sequence, the Laine strain differs from 269 Edmonston strain by $3.6 \%$. The L protein sequence seems to be more stable than other proteins 270 sequences, with only $1.2 \%$ mutations.

271 The entire coding sequence of the Hoedts was also analysed. As the sequences of the complete 272 genome of the reference strain for genotype C2 (Maryland.USA/77) was not available on 273 Genbank, the genome of the strain M185 [Alla et al., 2006] was sequenced and used as the wild 274 type strain for comparison. The results showed that the amino acid sequence divergence was 1.6, 
$2752.3,6.5,2.6,1.4$, and $0.9 \%$ for $\mathrm{N}, \mathrm{P}, \mathrm{M}, \mathrm{F}, \mathrm{H}$ and $\mathrm{L}$ respectively. The sequence analysis showed 276 that as in Laine strain, the start codon of the predicted M protein of the Hoedts strain was altered

277 to a threonine (Figure 3, Table 3). In the sequence of the F protein, a deletion of a $\mathrm{G}$ nucleotide 278 was detected at position 7031 which generate a reading frame shift that resulted in a premature 279 termination codon at amino acid position 535 (Figure 4). Taken together, these two evens lead to 280 a predicted altered $\mathrm{F}$ protein in the Hoedts strain which may be 11 amino acids shorter than the 281 one of the wild type strain of the same genotype, the M185 strain. In addition, a mutation M94V 282 was found in the $\mathrm{F}$ protein sequence. The analysis of the $\mathrm{H}$ sequence revealed that the 283 termination code is located at position 622 instead of 618 as in M185 strain (Table 3). Therefore, 284 the $\mathrm{H}$ protein of the Hoedts strain may have 4 amino acids more than M185 strain. In the N 285 protein, there was only 1 mutation $(\mathrm{S} 427 \mathrm{~N})$ in Hoedts strain. In contrast, the P protein contained 28612 amino acids changes. The L protein had only $0.8 \%$ mutations. 


\section{Discussion}

300 Subacute sclerosing panencephalitis (SSPE) is rare slowly progressive neurological disorder 301 caused by the persistent infection of human brain by a defective measles virus. Only wild-type 302 measles virus sequences have been found in SSPE cases [Rima and Duprex, 2005]. It is 303 estimated that about 1 out of 100,000 individuals infected by the measles virus will develop 304 SSPE. This study provides for the first time molecular data on SSPE cases from an historical and 305 a contemporaneous strains. These data are the basis that will help for a better understanding of 306 measles strain circulation in France.

307 Phylogenetic analyses from SSPE cases usually indicate the genotype circulating in the 308 geographic area where the patient contracted the primary measles infection [Rima et al., 1997].

309 This characteristic have been used to identify the source of virus strains causing SSPE [Bellini et 310 al., 2005; Forcic et al., 2004; Mahadevan et al., 2008; Miki et al., 2002].

311 The Laine strain, suspected to have circulated in France beetwen the 1940s and 1960s was found

312 to be close to an untyped SSPE strain reported previously to be circulating in the UK in 1956 [Jin 313 et al., 2002]. However, the Laine strain, could not be assigned a genotype. These findings

314 suggested that the Laine strain is an untyped historic strain probably circulating in France while 315 Edmonston strain was circulating in the USA (1954).

316 The high nucleotide identity, 97 and $98 \%$ between Hoedts strain and measles strain circulating in 317 the USA (Maryland.USA/77) and in Montreal in 1984 (Montreal.CAN/14.84) respectively, 318 confirmed the presumption that the patient would have been infected in the 1980's. Furthermore, 319 the genotype C2 was first detected in Europe in the 1970s where it was considered to be an 320 indigenous genotype and had recently been exported to the USA and Canada [Riddell et al., 
321 2005]. Thus the genotype C2 found is coherent with temporal and geographical distribution of 322 measles virus.

324 It is widely known that biased hypermutations are a hallmark of SSPE measles virus. Mutations 325 in the F protein of SSPE strains have been previously described [Billeter et al., 1994; Cattaneo et 326 al., 1988; Cattaneo et al., 1989]. So far these mutations resulted in three different type of F 327 protein: i) a F protein with an elongated carboxy-terminus tail [Ning et al., 2002], ii) a $\mathrm{F}$ protein 328 with a shortened carboxy-terminus [Billeter et al., 1994; Cattaneo et al., 1989; Ning et al., 2002], 329 iii) a F protein with unchanged length despite many amino acids changes [Ayata et al., 2007; 330 Ayata et al., 2010; Ning et al., 2002]. In this study, the cytoplasmic tail of the F protein, 331 predicted from sequences analysis of the gene, is altered in both SSPE strains and presented a 332 short tail pattern. However, the extent and mode of alteration was different in each strain. In 333 Laine strain, a premature stop codon was introduced by a point mutation leading to a stop codon 334 at amino acid position 546 while in Hoedts strain, a deletion of a $\mathrm{G}$ nucleotide at position 7031 335 was responsible for a reading frame shift which, subsequently results in a premature stop codon. 336 These two different mechanism are similar to those reported previously [Cattaneo et al., 1988;

337 Cattaneo et al., 1989; Ning et al., 2002]. It was reported recently that the F gene of SSPE viruses 338 is a major determinant of neurovirolence, [Ayata et al., 2010]. In the same report, it was 339 suggested that mutation T461I was sufficient to transform a non neuropathogenic wild type 340 measles virus into lethal virus. In this study, a different mutation I446T was found in the same 341 region of the F protein of both SSPE strains. This mutation seems to be very rare as it was found 342 in only $4 \%$ of sequences available in Genbank. It might therefore be interesting to study the role 343 of that specific mutation in the propagation of SSPE strains in the brain. A mutation M94V was 
344 observed in the F protein sequence of the Hoedts strain. It was reported that the amino acid at 345 position 94 , located in the putative heptad repeat $\mathrm{C}$ (HRC) domain of the $\mathrm{F}$ protein plays an 346 important role in the fusogenicity and glycoprotein interaction of measles virus [Plemper and 347 Compans, 2003]. This mutation has been reported for another SSPE strain (Osaka2), isolated in 348 Japan [Ayata et al., 2007].

349 The results of sequence analysis of the $\mathbf{M}$ gene complies with the published data i.e biased 350 hypermutations were found in the two SSPE strains. The initial codon was substituted by a 351 threonine, raising the question of the functionality of the resulting $M$ protein. It might be 352 interesting to analyze the $\mathrm{P} / \mathrm{M}$ intergenic region to explore whether there is an early start codon 353 for M protein. According to Ayata et al, [Ayata et al., 2002] mutation in the P3' untranslated 354 region can cause increased read-through at the $\mathrm{P} / \mathrm{M}$ junction and directly affects $\mathrm{M}$ gene 355 expression. A late stop codon was found in the Laine strain, suggesting that the M protein is 356 elongated. Similar results were reported previously [Forcic et al., 2004; Jin et al., 2002]. 357 However, in contrast to the present study, most of published studies reported truncated $\mathrm{M}$ 358 proteins. It has been reported that the V101A mutation, found in the predicted M Protein of both 359 SSPE strains, is sufficient to generate a functionally defective virus assembly [Runkler et al., 360 2007]. Among mutations found in the M protein sequence of the Laine strain, one was L165P 361 which is known to impair the ability of measles virus to produce cell-free progeny virus [Jiang et 362 al., 2009]. Biased and even point mutations in the $\mathrm{M}$ gene are known to render the $\mathrm{M}$ protein 363 insoluble, nonfunctional and therefore, impair the ability of the measles virus to produce cell-free 364 progeny virus [Jiang et al., 2009; Sheppard et al., 1986].

365 Compared to the M gene, the $\mathrm{H}$ gene of both SSPE strains were less mutated. However, in both 366 SSPE strains, the predicted H protein was longer than those of the wild type strains. In fact, the 
367 stop codon could not be found in the Laine stain, suggesting that the predicted $\mathrm{H}$ protein in this 368 strain is elongated. It might therefore be interesting to amplify the intergenic region between $\mathrm{H}$ 369 and $\mathrm{L}$ genes to ascertain whether the termination codon for $\mathrm{H}$ protein exists or not. Mutations 370 were found throughout the H protein of both SSPE strains, however, two of them (R7Q) and $371(\mathrm{Y} 12 \mathrm{H})$, were shared by both SSPE strains and were reported previously in SSPE strains isolated 372 in the United Kingdom in the 1950s [Jin et al., 2002] The study of their biological role should 373 give more insight onto the pathogenesis of SSPE.

374 In the present investigation, the complete sequences of the N, P, F, M, H and L gene of two 375 SSPE strains were analyzed. The genotypes of measles virus identified in SSPE cases provided 376 information about the circulation of measles strains in France in the 1940-1960s and 1980s. 377 Sequences analyses results showed that the N, P and L genes had no exceptional mutations. In 378 contrast, striking alterations where observed in the sequence of $\mathrm{M}$ protein which has an altered 379 start codon, in $\mathrm{H}$ protein where elongated $\mathrm{C}$-terminal tail was found and in the $\mathrm{F}$ protein which 380 was partially deleted. Detailed virological and immunological studies will be necessary to 381 explore the biological impacts of these mutations for a better comprehension of SSPE 382 pathogenesis.

385 Acknowledgments

386 The authors are grateful to Dr F.L. Cosset, Inserm U758 (Lyon, France) for his support, Dr A. 387 Alla, National institute of Hygiene (Rabat, Morocco) for measles strain M185. This work was 388 supported by the Institute de Veille Sanitaire, France and INSERM. 
390

391

392

393

394

395

396

397

398

399

400

401

402

403

404

405

406

407

408

409

410

411

412

413

414

415

416

417

418

419

420

421

422

423

424

425

426

427

428

429

430

431

432

\section{References}

Alla A, Waku-Kouomou D, Benjouad A, Elaouad R, Wild TF. 2006. Rapid diversification of measles virus genotypes circulating in Morocco during 2004-2005 epidemics. J Med Virol 78:1465-1472.

Ayata M, Komase K, Shingai M, Matsunaga I, Katayama Y, Ogura H. 2002. Mutations affecting transcriptional termination in the $\mathrm{p}$ gene end of subacute sclerosing panencephalitis viruses. J Virol 76:13062-13068.

Ayata M, Shingai M, Ning X, Matsumoto M, Seya T, Otani S, Seto T, Ohgimoto S, Ogura H. 2007. Effect of the alterations in the fusion protein of measles virus isolated from brains of patients with subacute sclerosing panencephalitis on syncytium formation. Virus Res 130:260-268.

Ayata M, Takeuchi K, Takeda M, Ohgimoto S, Kato S, Sharma LB, Tanaka M, Kuwamura M, Ishida H, Ogura H. 2010. The F gene of the Osaka-2 strain of measles virus derived from a case of subacute sclerosing panencephalitis is a major determinant of neurovirulence. $\mathbf{J}$ Virol 84:11189-11199.

Bellini WJ, Rota JS, Lowe LE, Katz RS, Dyken PR, Zaki SR, Shieh WJ, Rota PA. 2005. Subacute sclerosing panencephalitis: more cases of this fatal disease are prevented by measles immunization than was previously recognized. J Infect Dis 192:1686-1693.

Billeter MA, Cattaneo R, Spielhofer P, Kaelin K, Huber M, Schmid A, Baczko K, ter Meulen V. 1994. Generation and properties of measles virus mutations typically associated with subacute sclerosing panencephalitis. Ann N Y Acad Sci 724:367-377.

Cattaneo R, Schmid A, Eschle D, Baczko K, ter Meulen V, Billeter MA. 1988. Biased hypermutation and other genetic changes in defective measles viruses in human brain infections. Cell 55:255-265.

Cattaneo R, Schmid A, Spielhofer P, Kaelin K, Baczko K, ter Meulen V, Pardowitz J, Flanagan S, Rima BK, Udem SA, et al. 1989. Mutated and hypermutated genes of persistent measles viruses which caused lethal human brain diseases. Virology 173:415-425.

Forcic D, Baricevic M, Zgorelec R, Kruzic V, Kaic B, Marina BM, Sojat LC, Tesovic G, Mazuran R. 2004. Detection and characterization of measles virus strains in cases of subacute sclerosing panencephalitis in Croatia. Virus Res 99:51-56.

Garg RK. 2008. Subacute sclerosing panencephalitis. J Neurol 255:1861-1871.

Jiang DP, Ide YH, Nagano-Fujii M, Shoji I, Hotta H. 2009. Single-point mutations of the M protein of a measles virus variant obtained from a patient with subacute sclerosing panencephalitis critically affect solubility and subcellular localization of the M protein and cell-free virus production. Microbes Infect 11:467-475.

Jin L, Beard S, Hunjan R, Brown DW, Miller E. 2002. Characterization of measles virus strains causing SSPE: a study of 11 cases. J Neurovirol 8:335-344.

Kouomou DW, Nerrienet E, Mfoupouendoun J, Tene G, Whittle H, Wild TF. 2002. Measles virus strains circulating in Central and West Africa: Geographical distribution of two B3 genotypes. J Med Virol 68:433-440.

Mahadevan A, Vaidya SR, Wairagkar NS, Khedekar D, Kovoor JM, Santosh V, Yasha TC, Satishchandra P, Ravi V, Shankar SK. 2008. Case of fulminant-SSPE associated with measles genotype D7 from India: an autopsy study. Neuropathology 28:621-626. 
Miki K, Komase K, Mgone CS, Kawanishi R, Iijima M, Mgone JM, Asuo PG, Alpers MP, Takasu T, Mizutani T. 2002. Molecular analysis of measles virus genome derived from SSPE and acute measles patients in Papua, New Guinea. J Med Virol 68:105-112.

Ministère-de-la-santé-DGS. 2008. Guide des vaccinations. INPES:309-318.

Ning X, Ayata M, Kimura M, Komase K, Furukawa K, Seto T, Ito N, Shingai M, Matsunaga I, Yamano T, Ogura H. 2002. Alterations and diversity in the cytoplasmic tail of the fusion protein of subacute sclerosing panencephalitis virus strains isolated in Osaka, Japan. Virus Res 86:123-131.

Oldstone MB, Dales S, Tishon A, Lewicki H, Martin L. 2005. A role for dual viral hits in causation of subacute sclerosing panencephalitis. The Journal of experimental medicine 202:1185-1190.

Plemper RK, Compans RW. 2003. Mutations in the putative HR-C region of the measles virus F2 glycoprotein modulate syncytium formation. J Virol 77:4181-4190.

Riddell MA, Rota JS, Rota PA. 2005. Review of the temporal and geographical distribution of measles virus genotypes in the prevaccine and postvaccine eras. Virol J 2:87.

Rima BK, Duprex WP. 2005. Molecular mechanisms of measles virus persistence. Virus Res 111:132-147.

Rima BK, Earle JA, Baczko K, ter Meulen V, Liebert UG, Carstens C, Carabana J, Caballero M, Celma ML, Fernandez-Munoz R. 1997. Sequence divergence of measles virus haemagglutinin during natural evolution and adaptation to cell culture. J Gen Virol 78:97-106.

Rota PA, Bloom AE, Vanchiere JA, Bellini WJ. 1994. Evolution of the nucleoprotein and matrix genes of wild-type strains of measles virus isolated from recent epidemics. Virology 198:724-730.

Runkler N, Pohl C, Schneider-Schaulies S, Klenk HD, Maisner A. 2007. Measles virus nucleocapsid transport to the plasma membrane requires stable expression and surface accumulation of the viral matrix protein. Cellular microbiology 9:1203-1214.

Sheppard RD, Raine CS, Bornstein MB, Udem SA. 1986. Rapid degradation restricts measles virus matrix protein expression in a subacute sclerosing panencephalitis cell line. Proceedings of the National Academy of Sciences of the United States of America 83:7913-7917.

Souraud JB, Faivre A, Waku-Kouomou D, Gaillard T, Aouad N, Meaudre E, Wild FT, Fouet B, Soulard R. 2009. Adult fulminant subacute sclerosing panencephalitis: pathological and molecular studies--a case report. Clinical neuropathology 28:213-218.

Tamura K, Dudley J, Nei M, Kumar S. 2007. MEGA4: Molecular Evolutionary Genetics Analysis (MEGA) software version 4.0. Mol Biol Evol 24:1596-1599.

Tipples GA, Gray M, Garbutt M, Rota PA. 2004. Genotyping of measles virus in Canada: 19792002. J Infect Dis 189 Suppl 1:S171-176.

Waku-Kouomou D, Alla A, Blanquier B, Jeantet D, Caidi H, Rguig A, Freymuth F, Wild FT. 2006. Genotyping measles virus by real-time amplification refractory mutation system PCR represents a rapid approach for measles outbreak investigations. J Clin Microbiol 44:487-494.

Waku-Kouomou D, Freymuth F, du Chatelet IP, Wild TF, Horvat B. 2010. Co-circulation of multiple measles virus genotypes during an epidemic in France in 2008. J Med Virol 82:1033-1043. 
478 Waku-Kouomou D, Landreau D, Olivier S, Palmyre P, Benoit-Catin T, Freymuth F, Wild TF. 479 2007. Molecular characterization of measles virus circulating in the Indian Ocean Islands during 2005-2006 and in France in 2006. J Med Virol 79:1381-1387.

WHO. 2001a. Standardization of nomenclature for describing the genetic characteristics of wildtype measles viruses (partI). WklyEpidemiolRec 76:241-248.

WHO. 2005. New genotype of measles virus and update on global distribution of measles genotype. WklyEpidemiolRec 80:341-352.

486 WHO. 2009. Measles. Fact sheet

487286.

488 Wild TF, Giraudon P, Bernard A, Huppert J. 1979. Isolation and characterisation of a defective 489 measles virus from a subacute sclerosing panencephalitis patient. J Med Virol 4:103-114.

490 Zandotti C, Jeantet D, Lambert F, Waku-Kouomou D, Wild F, Freymuth F, Harle JR, de 491 Lamballerie X, Charrel RN. 2004. Re-emergence of measles among young adults in 492

493

494

495

496

497

498

499

500

501

502

503

504

505

506

507

508

509

510

511

512

513 Marseilles, France. Eur J Epidemiol 19:891-893. 
Table 1: Measles virus strain analyzed in this study

\begin{tabular}{|l|l|l|l|l|}
\hline Measles virus strains & Lab name & Description & Genotype & Genebank Accession Number \\
\hline Edmonston-wt-USA/54 & Edmonston & Wild type MV strain isolated in USA in 1954 & A & AF266291 \\
\hline MvilLyon.FRA/77 & Laine & SSPE MV strain isolated in France in 1977 & unknown & This study \\
\hline Mvs/Toulon.FRA $08.07^{\mathrm{a}}$ & Hoedts & SSPE MV strain isolated in France in 2007 & C2 & This study \\
\hline Mvi/Temara.MOR/24.03 & M185 & Wild type MV strain isolated in Morroco in 2003 & C2 & Alla et al., 2006, and this study \\
\hline
\end{tabular}

${ }^{a}$ Entire viral genome sequenced in this study

514

${ }^{b}$ Entire viral genome sequenced in this study except $H$ gene (alla et al, 2006)

Table 2: Sequences of primers used for PCR amplification

\begin{tabular}{|c|c|c|c|}
\hline Gene & primers name & Primers sequences & $\begin{array}{l}\text { PCR product } \\
\text { size }(\mathrm{pb})\end{array}$ \\
\hline \multirow{2}{*}{$\mathbf{N}$} & N1 bis $(+)$ & 5' GATCCTATTATCAGGGACAAGAGC3' & \multirow[b]{2}{*}{1650} \\
\hline & N4 bis(-) & 5' GATGTTGTTCTGGTCCTCGGCCTC3' & \\
\hline \multirow{4}{*}{$\mathbf{P}$} & P5's2(+) & 5' GGGAAGATCTTCCAGCCAACCAACCATC3' & \multirow[b]{2}{*}{1014} \\
\hline & Pseq 3(-) & 5' GATGTCTTGGACATCGGAGAAC3' & \\
\hline & Pseq2(+) & 5' TGTGAGCAATGCCGCACTGATAC3' & \multirow[b]{2}{*}{730} \\
\hline & P3'(-) & 5' GAAGATCTTCCGGCAGGTAAGTTGAGC3' & \\
\hline \multirow{4}{*}{ M } & $\mathrm{M} 1(+)$ & 5' CTTAGGAGCAAAGTGATTGCCTC3' & \multirow[b]{2}{*}{582} \\
\hline & M2(-) & 5' GACCGATCTGAATTCCAGCATTC3' & \\
\hline & $\begin{array}{ll}1 / 1 \\
M 3(+)\end{array}$ & 5' GTTAATCTGATACCGCTCGATACC3' & \multirow[b]{2}{*}{633} \\
\hline & M4bis(-) & 5' CGCTTGGTCCGTGGAGTCTTTCG3' & \\
\hline \multirow{4}{*}{$\mathbf{F}$} & $\mathrm{MF} 1(+)$ & 5' CCCAGAATCAAGACTCATCC3' & \multirow[b]{2}{*}{880} \\
\hline & MF2(-) & 5' CGTCGGATAGGCTATACTGAGGAC3' & \\
\hline & MF3(+) & 5' GGCATCTTAGAGAGCAGAGG3' & \multirow{4}{*}{$\frac{932}{1251}$} \\
\hline & \begin{tabular}{|l|l} 
MF4(-) \\
\end{tabular} & 5' CGAAGAGGAGACTTGTGGGAAC3' & \\
\hline \multirow{4}{*}{ H } & gh004(+) & 5' GTGCAAGATCATCCACAATGTCACC3' & \\
\hline & mh1251(-) & 5' CGTATGAAGGAATCCTGTTATC3' & \\
\hline & gh1029(+) & 5' CCAACCGACATGCAATCCTGG3' & \multirow{2}{*}{914} \\
\hline & mh1922(-) & 5' GTATGCCTGATGTCTGGGTGAC3' & \\
\hline \multirow{14}{*}{$\mathbf{L}$} & $\mathrm{L} 1 \mathrm{~S}(+)$ & 5' GTGAAATAGACATCAGAATTAAG 3' & \multirow[b]{2}{*}{1092} \\
\hline & \begin{tabular}{|l|l|} 
L1as(-) \\
\end{tabular} & 5' GTCAGATGTATGTCATCAGTTATG 3' & \\
\hline & \begin{tabular}{|l}
$\mathrm{L} 2 \mathrm{~s}(+)$ \\
\end{tabular} & 5' GCTTTACTGAAATACATGATGTTCTTGAC 3' & \multirow{2}{*}{1127} \\
\hline & L2as(-) & 5' GCCTCTGTGCAAACAAGCTGATGGTC 3' & \\
\hline & $\begin{array}{ll}\mathrm{L} 3 \mathrm{~s}(+) \\
\end{array}$ & 5' GACCAAGACACTGATCATCCG 3' & \multirow[b]{2}{*}{1121} \\
\hline & \begin{tabular}{|l|l|} 
L3as $(-)$ \\
\end{tabular} & 5' GAGGAGTCTAGTGATGCTCTGGACACATAC 3' & \\
\hline & L4s2(+) & 5' GATTCTCGCCTCACTAATGCC 3' & \multirow{2}{*}{718} \\
\hline & \begin{tabular}{|l} 
L4as2(-) \\
\end{tabular} & 5' GTTTCCTTGTCAATATCATCCAG 3' & \\
\hline & L4s3(+) & 5' GTGTGGATCAGTCAACTACG 3' & \multirow{2}{*}{911} \\
\hline & L4as3(-) & 5' GAATAATCTTGGCTCTATGAGC 3' & \\
\hline & $\overline{L 5 s(+)}$ & 5' GCTAAGTCCACAGCACTATCTATG 3' & \multirow{2}{*}{1094} \\
\hline & \begin{tabular}{|l} 
L5as $(-)$ \\
\end{tabular} & 5' CTCTTTATAAGTGATCAACATAGAACC 3' & \\
\hline & L6s $(+)$ & 5' CTGTTGAGATATCAACATTAATTAGGAG 3' & \multirow{2}{*}{1308} \\
\hline & \begin{tabular}{|ll} 
L6as(-) \\
L6as
\end{tabular} & 5' GCAAATAATGCCTAACCACCTAGGGCAG 3' & \\
\hline
\end{tabular}


Table 3 : SSPE stains specific amino acid mutations

\begin{tabular}{|c|c|c|c|c|c|}
\hline Gene & $\begin{array}{l}\text { Amino acid } \\
\text { position }\end{array}$ & $\begin{array}{c}\text { Edmonston strain } \\
\text { (Genotype A) }\end{array}$ & $\begin{array}{l}\text { Laine strain } \\
\text { (SSPE) }\end{array}$ & $\begin{array}{c}\text { M185 strain } \\
\text { (Genotype C2) }\end{array}$ & $\begin{array}{c}\text { Hoedts strain } \\
\text { (SSPE) }\end{array}$ \\
\hline \multirow{2}{*}{$\mathbf{P} / \mathbf{V}$} & 225 & $\mathrm{G}$ & $E$ & $G$ & $E$ \\
\hline & 300 & stop & $\mathbf{Q}$ & stop & stop \\
\hline \multirow{15}{*}{ M } & 1 & $\mathrm{M}$ & $\mathrm{T}$ & $\bar{M}$ & $\mathrm{~T}$ \\
\hline & 5 & Y & $\mathrm{H}$ & Y & $\mathrm{H}$ \\
\hline & 65 & L & $P$ & L & $\mathrm{P}$ \\
\hline & 97 & L & $P$ & L & $\mathrm{P}$ \\
\hline & 101 & V & A & V & A \\
\hline & 135 & $\mathrm{~F}$ & $\mathrm{~L}$ & $\mathrm{~F}$ & $\mathrm{~L}$ \\
\hline & 165 & $\mathbf{L}$ & $\mathbf{P}$ & L & $\mathbf{L}$ \\
\hline & 170 & Y & $\mathrm{H}$ & Y & $\mathrm{H}$ \\
\hline & 180 & $F$ & L & $F$ & L \\
\hline & 232 & Y & $\mathrm{H}$ & Y & $\mathrm{H}$ \\
\hline & 248 & $F$ & $S$ & $F$ & $S$ \\
\hline & 291 & L & P & L & $P$ \\
\hline & 303 & V & A & V & A \\
\hline & 335 & stop & $\mathbf{Q}$ & stop & stop \\
\hline & 350 & - & stop & - & - \\
\hline \multirow{4}{*}{$F$} & 94 & $\bar{M}$ & $M$ & $M$ & $\bar{V}$ \\
\hline & 449 & I & $\mathrm{T}$ & I & $\mathrm{T}$ \\
\hline & 535 & $\mathbf{L}$ & $\mathbf{P}$ & $\mathbf{L}$ & stop \\
\hline & 546 & $\mathbf{Y}$ & stop & $\mathbf{Y}$ & - \\
\hline \multirow{4}{*}{ H } & 7 & $\bar{R}$ & $\mathrm{Q}$ & $\bar{R}$ & $\bar{Q}$ \\
\hline & 12 & Y & $\mathrm{H}$ & $Y$ & $\mathrm{H}$ \\
\hline & 618 & stop & $\mathbf{Q}$ & stop & W \\
\hline & 622 & - & $?$ & - & stop \\
\hline \multirow{2}{*}{ L } & 723 & $\bar{Y}$ & $\mathrm{C}$ & $\bar{Y}$ & C \\
\hline & 1887 & $\mathrm{D}$ & $\mathrm{N}$ & D & $\mathrm{N}$ \\
\hline
\end{tabular}

Important mutations specific to only one of the two SSPE strains are indicated in bold. The question mark (?) represented unanalysed amino acid. 


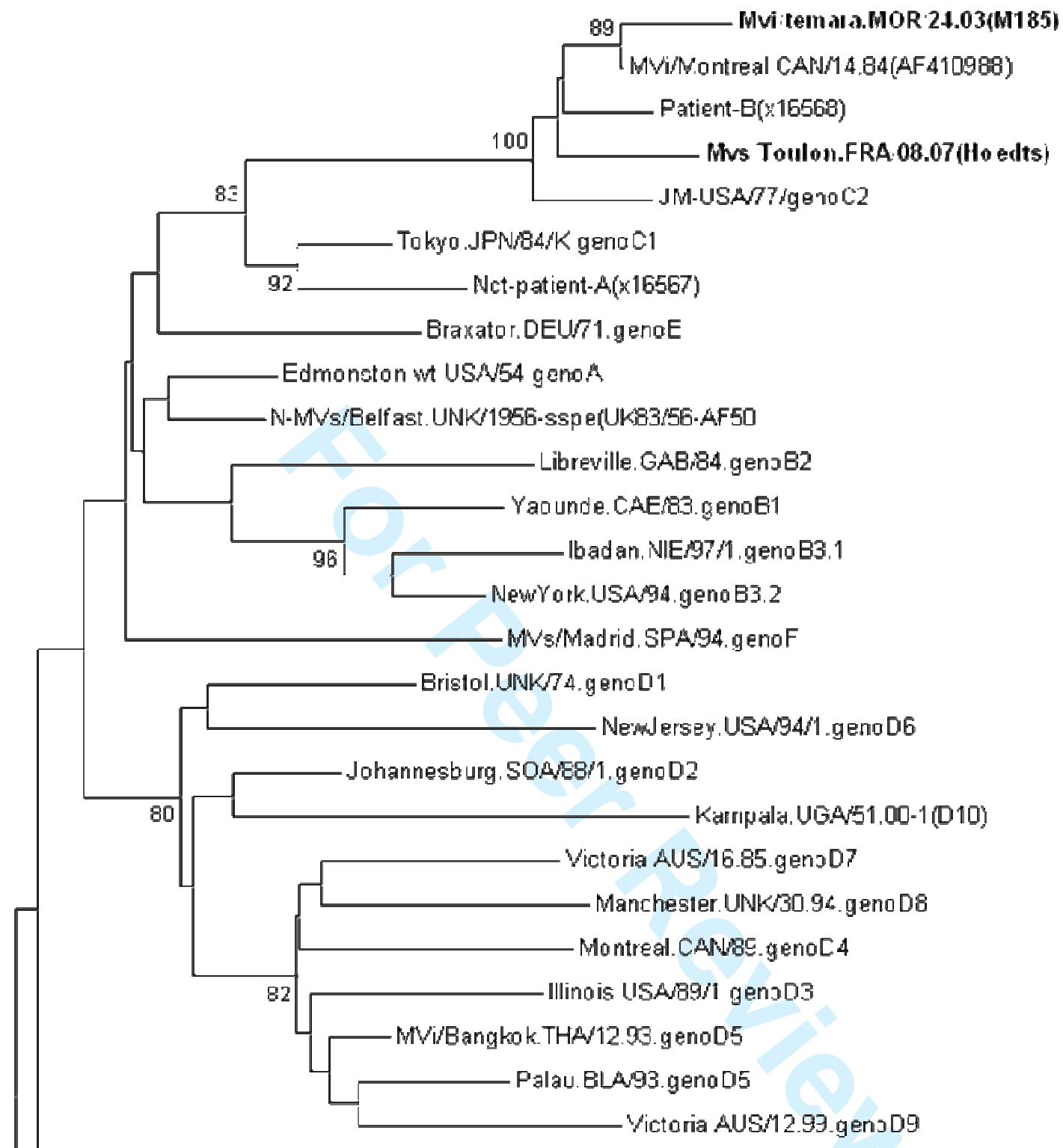

Mvi. Lyon.FRA:77(Laine)

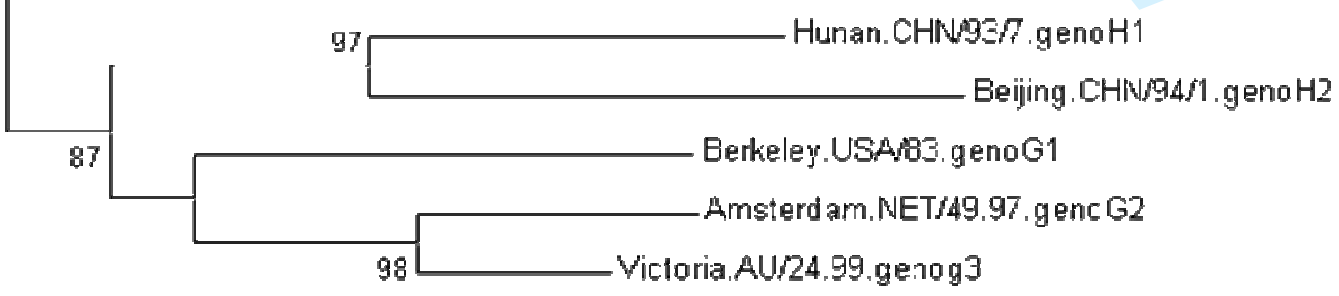

537 Figure 1: Phylogenetic tree based on the sequences of the hypervariable region of the $\mathrm{N}$ gene, showing the two 538 SSPE strains (Laine and Hoedts) isolated in France in1977 and 2007 respectively. Other SSPE strain (Patient B) and 539 Wild type measles strains (M185) of genotype C2, were also included. Sequences analysed in this study are in bold. 540 Significant bootstrap values $(>80)$ are indicated. 


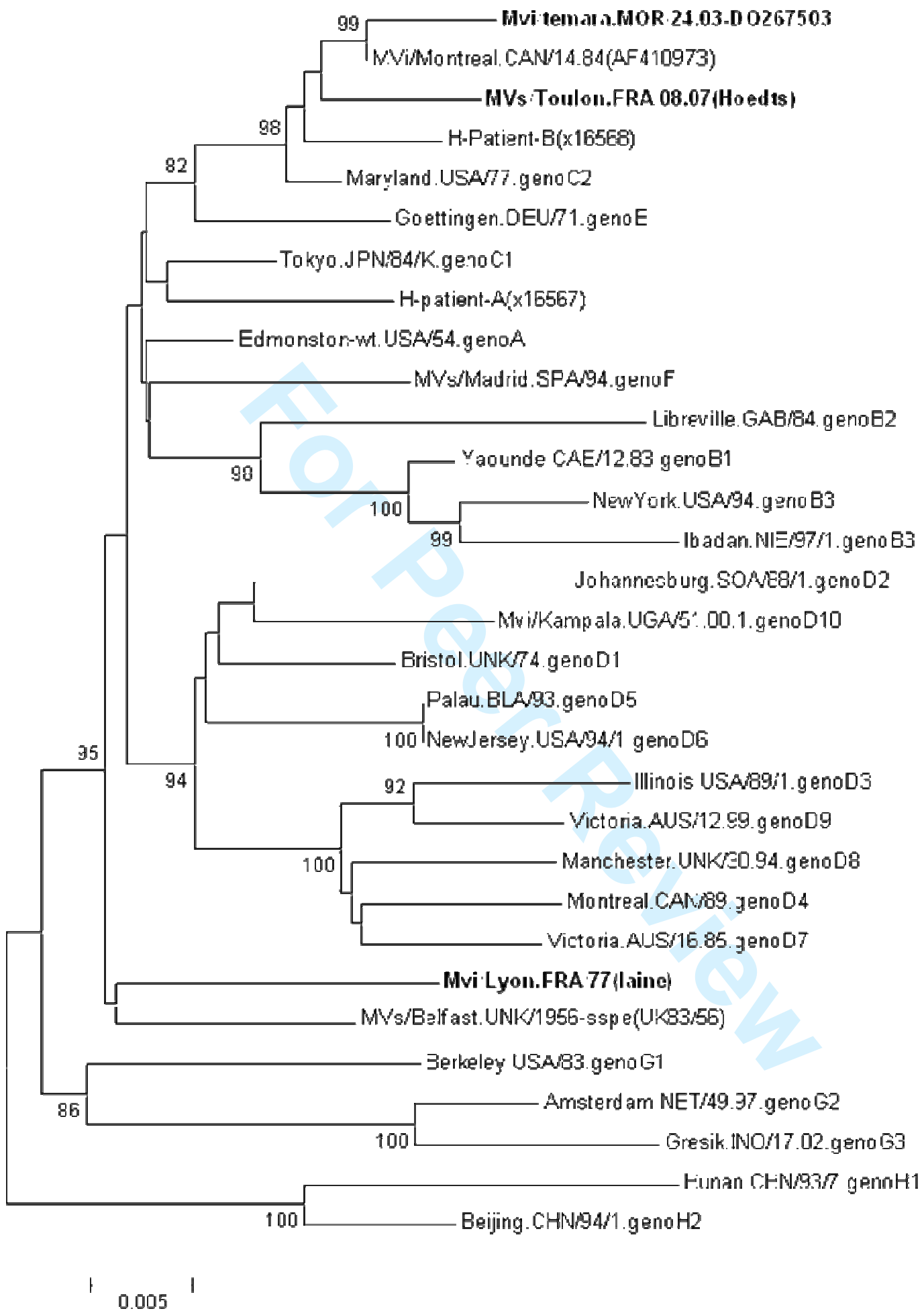

542 Figure 2: Phylogenetic tree based on the sequences of entire $\mathrm{H}$ gene, showing the two SSPE strains (Laine and 543 Hoedts) isolated in France in 1977 and 2007 respectively. Other SSPE strain (Patient B) and Wild type measles 544 strains (M185) of genotype C2, were also included. Sequences analysed in this study are in bold. Significant 545 bootstrap values $(>80)$ are indicated. 
\#M-Edmonst on-wt. USA/54.genoA \#M-MVs/Lyon.FRA/ 77 (Laine)
\#M-Mvs/Toulon.FRA/08.07 (Hoedts) \#M-Mvs/Toulon.FRA/08.07 (Hoedts)
\#M-Mvi/temara.MOR/24.03 (M1 85) \#Mary land. USA/77.genoC2 ( JM-77)

\#M-Edmonston-wt. USA/54.genoA \#M-MVs/Lyon.FRA/ 77 (Laine) \#M-Mvs/Toulon.FRA/08.07 (Hoedts) \#M-Mvi/temara.MOR/24.03 (M1 85)

\#M-Edmonst on-wt. USA/54.genoA \#M-MVs/Lyon.FRA/ 77 (Laine) \#M-Mvs/Toulon.FRA/08.07 (Hoedts) \#M-Mvi/temara.MOR/24.03 (MI 85) \#Mary land. USA/77.genoC2 (JM-77)

\#M-Edmonston-wt. USA/5 4 . genoA \#M-MVs/Lyon.FRA/77 (Laine) \#M-Mvi/temara.MOR/24.03 (M1 85) \#Maryland. USA/77.genoC2 ( JM-77)

\#M-Edmonst on-wt. USA/54.genoA \#M-MVs/Lyon.FRA/77 (Laine) \#M-Mvs/Toulon.FRA/08.07 (Hoedts) \#M-Mvi/temara.MOR/24.03 (M1 85) \#Mary land. USA/77.genoC2 (JM-77) \#M-Mvs/Toulon.FRA/08.07 (Hoedts) \#Maryland. USA/77.genoC2 (JM-77)

MTE IYDFDKS AWDIKGSIAP IOPTTYSDGR LVPOVRVIDP GLGDRKDECF MYMFLLGVVE DSDPLGPPIG RAFGSLPLGV T.S.H.P....R..... T...H...........P....S THTP.P.AA. ..P..T. .P...SA

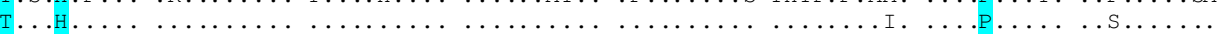

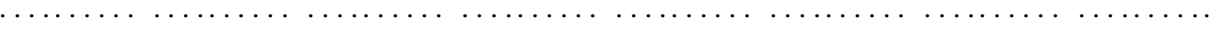

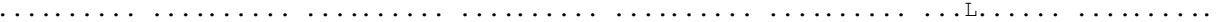
GRSTAKPEKL LKEATELDIV VRRTAGLNEK LVFYNNTPLT LLTPWRKVLT TGSVFNANQV CSAVNLIPLD TPQRFRVVYM

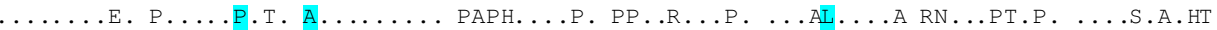

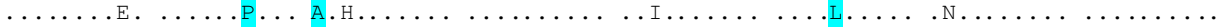

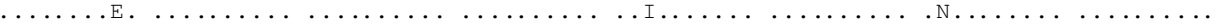

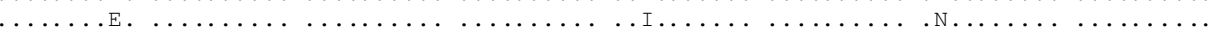
SITRLSDNGY YTVPRRMLEF RSVNAVAFNL LVTLRIDKAI GPGKIIDNTE QLPEATFMVH IGNFRRKKSE VYSADYCKMK

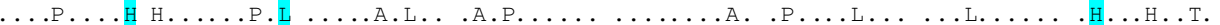

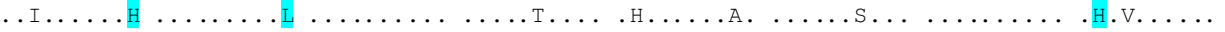

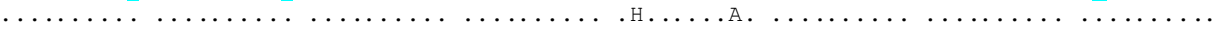
IEKMGLVFAL GGIGGTSLHI RSTGKMSKTL HAOLGFKKTL CYPLMDINED LNRLLWRSRC KIVRTOAVLO PSVPOEFRIY

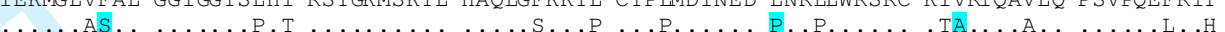

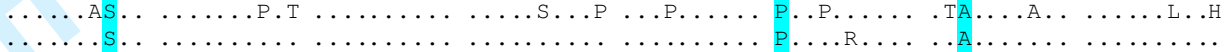

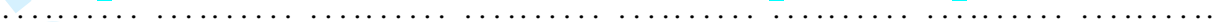

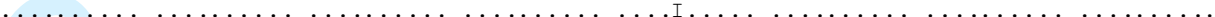

DDVIINDDQG LFKVL *TVVP SNARKRPPSQ * [351] ...T.... P..A.QSA. ........ [351] K...S...S.....???? ?????????? ? [351] $\ldots \ldots \ldots \ldots \ldots$ ???? ?????????? ? [351]

Figure 3: Amino acid sequence alignment of the $M$ protein. Amino acid identity are given as dot and an amino acid indicates disagreement with Edmonston strain. The star $(*)$ indicates the stop codon. The question mark(?) were added for the purpose of alignment to obtain equal sequence length for all the sequences. Amino acid specific to SSPE strains (Laine and Hoedts) are indicated.

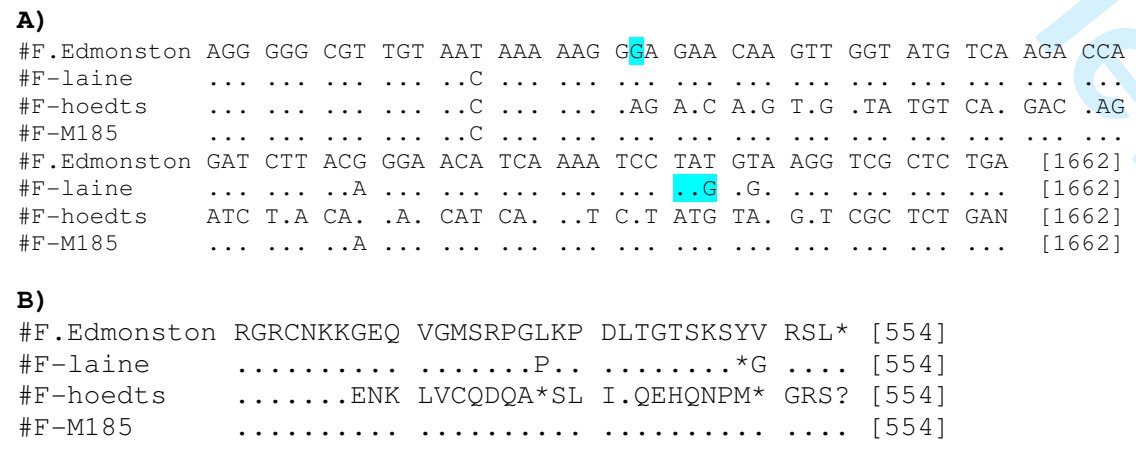

Figure 4: Alignment of nucleotide sequence (A) and the related amino acid sequence (B) of the F gene (C-terminal partial sequence). Nucleotide and amino acids identities are given as dot and a nucleotide or an amino acid indicates disagreement with Edmontston strain. The star $\left(^{*}\right)$ indicates the stop codon. The letter $\mathrm{N}$ in the the nucleotide sequence and the question mark (?) in amino acid sequence were added for the purpose of alignment. The nucleotide $\mathrm{G}$ deleted in the Hoedts sequence is indicated and the premature stop codon of SSPE strains (Laine and Hoedts) are also indicated. 